\title{
Synthesis, Characterization and Morphological Study of Nicotinamide and $p$-Coumaric Acid Cocrystal
}

\author{
Mohamad Nor Amirul Azhar Kamis ${ }^{1,2}$, Hamizah Mohd Zaki ${ }^{1,2,}$, Nornizar Anuar ${ }^{3}$, and Mohammad \\ Noor Jalil ${ }^{1}$
}

${ }^{1}$ Faculty of Applied Sciences, Universiti Teknologi MARA, 40450 Shah Alam, Selangor, Malaysia

${ }^{2}$ Atta-ur-Rahman Institute for Natural Product Discovery, Universiti Teknologi MARA (UiTM),

Puncak Alam Campus, 42300 Bandar Puncak Alam, Selangor, Malaysia

${ }^{3}$ Faculty of Chemical Engineering, Universiti Teknologi MARA, 40450 Shah Alam, Selangor, Malaysia

\begin{abstract}
*Corresponding author:
tel: $+603-55445608$

email: hamiz410@salam.uitm.edu.my

Received: April 30, 2019

Accepted: June 20, 2019

DOI: $10.22146 /$ ijc. 45530

Abstract: Cocrystallization is one of the potent methods used to modify the physicochemical properties of drugs. Cocrystal of nicotinamide (NIC):p-coumaric acid (COU) was synthesized by a slow evaporation method using acetonitrile. The cocrystals with different feed molar ratios (NIC:COU : 1:1, 1:2, and 2:1) were characterized using DSC, PXRD, and FTIR, which revealed the formation of different polymorphs for each feed molar ratio. A single crystal of the NIC:COU (1:1) cocrystal was analyzed using single crystal X-ray diffraction (SCD), and ${ }^{1} H-N M R$ revealed a greater cocrystal structure stability compared to the previously published cocrystal. The intermolecular hydrogen bonds, $\mathrm{N}-\mathrm{H} \cdots \mathrm{O}$, and $\mathrm{O}-\mathrm{H} \cdots \mathrm{O}$ interactions played a major role in stabilizing the cocrystal structure. A molecular modeling technique was used for prediction, and surface chemistry assessment of the morphology showed an elongated (along the y-axis) octagonal crystal shape, which was in a reasonable agreement with the experimental crystal morphology. The reduction in values of the cocrystal solubility in ethanol was supported by the DSC data and simulation of crystal facets, where most of the crystal facets exposed to polar functional groups. At the concentration of $31.3 \mu \mathrm{M}$, NIC:COU (1:1) cocrystal showed more effective DPPH scavenging with $77.06 \%$ increased activity compared to NIC at the same concentration.
\end{abstract}

Keywords: physicochemical properties; cocrystal; molecular interaction; single crystal $X R D$; computational simulation

\section{- INTRODUCTION}

Pharmaceutical cocrystal is defined as multiple component crystals that contains an active pharmaceutical ingredient (API) and one or more pharmaceutically acceptable coformers with a welldefined stoichiometry through non-covalent interactions. The molecules in the cocrystal lattice are usually linked by hydrogen bonds, which tend to collapse once dissolved in a solvent if the interactions are weak. The formation of cocrystals is able to fine-tune or even customize the physicochemical properties of APIs in terms of their solubility, dissolution rate, moisture sorption, and stability without affecting the intrinsic bioactivity [1-2]. The cocrystals can be prepared by using several methods such as solution cooling, ambient co-milling, cryogenic co-grinding, slurry, solvent evaporation, or melt [3-4].

Nicotinamide (NIC) is an API, commercially known as vitamin $B_{3}$, is a water-soluble vitamin which able to form hydrogen bonds with other compounds containing hydrogen bond donor and acceptor groups [5]. There are four known polymorphs of NIC, the most stable at $126-128^{\circ} \mathrm{C}$, followed by the metastables at $112-$ $117^{\circ} \mathrm{C}, 107-111^{\circ} \mathrm{C}$, and $101-103{ }^{\circ} \mathrm{C}$ respectively [6]. NIC is widely used for acne vulgaris, anti-inflammatory, and exhibits many potential promising applications 
such as improving the cognition in Alzheimer's disease transgenic mice, and able to reduce hyperpigmentation for patients with melisma [7].

The nitrogen atom on the pyridine ring of NIC often forms strong hydrogen bonds with the carboxylic acid group in the cocrystal designs [8-14], which makes the COU ( $p$-coumaric acid) as the best compound to be used as the cocrystal former. The successful carboxylic acids used in the cocrystallization with NIC were ibuprofen (both $R / S$ and $S$ forms), salicylic acid, fenbufen, and flurbiprofen [15], fenamic acid [11], prulifloxacin [4], and (R)-mandelic acid [16]. Other compounds used in the cocrystallization with NIC were artesunate [17], baicalein [2], carbamazepine [5,18], celecoxib [19], ethylparaben [20], and simvastatin [21]. The single crystal of NIC:theophylline cocrystal showed the participation of the amide group forming the $\mathrm{N}-\mathrm{H} \cdots \mathrm{O}$, and $\mathrm{O} \cdots \mathrm{H}-\mathrm{N}$ hydrogen bonds [22-23].

Nicotinamide (NIC), Fig. 1(a) is used in many cocrystallization experiments due to the presence of two hydrogen bonding groups ready to form the intermolecular hydrogen bond. The amide group has two proton donors and two lone pairs on the carbonyl group, which act as hydrogen bond acceptors. Another hydrogen bond acceptor group is the nitrogen atom on the pyridine ring with a lone pair, which is reported as the best hydrogen bonding acceptor [24]. Etter's empirical rule specified that the best proton donor and acceptor remained after intramolecular hydrogen bond formation will form the intermolecular hydrogen bonds [25]. The carboxylic acid proton was reported as the best hydrogen bond donor, which will interact with the nitrogen atom of pyridine ring (best hydrogen bond acceptor) as observed occurring in 10 out of 11 of the reported NIC-acid cocrystals [24].

The donor/acceptor pair of amide syn-proton and the carbonyl oxygen of the amide can form a homomeric $\mathrm{R}_{2}^{2}$ (8) hydrogen bond ring [26-27]. The hydrogen bonding between the carboxylic acid group with the amide of NIC forms the heteromeric $\mathrm{R}_{2}^{2}(8)$ hydrogen bonding dimer [28].

$p$-Coumaric acid (COU), Fig. 1(b) is one of the hydrocinnamic acids which widely spread in the plant

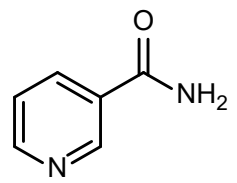

(a)

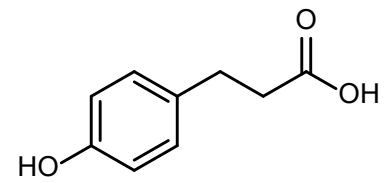

(b)
Fig 1. (a) Nicotinamide (NIC), (b) p-Coumaric acid $(\mathrm{COU})$

kingdom with useful biological activities, such as antioxidant, anti-inflammatory, antimicrobial, anticancer, antiplatelet, anti-melanogenic, antidiabetic, cardioprotective, suppression of tumor growth, and anti-anxiety activities [29-30]. $p$-Coumaric acid can be found abundantly as compared with the other two isomers, ortho-, meta-coumaric acid [31-32]. COU has been widely used in food, medicine, and cosmetic industries, which able to treat cosmetic imperfection [7,33-34].

COU has a hydroxyl group at para position of the aromatic ring and a carboxylic acid functional group, which are the possible sites for the hydrogen bonding to occur. A study between COU and quinine resulted in the formation of hybrid salt-cocrystal solvate composed of a quinine ion $\left(\mathrm{Q}^{+}\right)$, a coumarate ion $\left(\mathrm{COU}^{-}\right)$, water molecule, and methanol molecule, where water and methanol molecules acted as a bridge connecting $\mathrm{Q}^{+}$and $\mathrm{COU}^{-}$ions [35]. A study on a cocrystal between $\mathrm{COU}$ and theophylline and caffeine showed the utilization of both proton donor groups of $\mathrm{COU}$, which built the cocrystal structures [31]. The cocrystal of COU with isoniazid showed that $-\mathrm{OH}$ phenol of $\mathrm{COU}$ prefers to form a hydrogen bond with the best hydrogen bond donor of the nitrogen atom of the pyridine ring of isoniazid [25,32], which does not follow the hydrogen bonding hierarchy. The same case has been observed in cocrystal between caffeic acid and isoniazid [36]. These occurrences show that the behavior of hydrogen bonding interactions between molecules is still specifically cannot be predicted.

Bevill et al. [7] had successfully synthesized and characterized the NIC:COU cocrystal using methanol with three polymorphic forms of 1:1 cocrystal, and one 1:2 cocrystal resulted from the induction in water. However, the study focused on the cocrystal 
characterization, relative solid-state stability, and conversion to alternate stoichiometries of the polymorphic forms [7].

The molecular modeling simulation method is a widely used technique in crystal research [37], commonly used to predict crystal morphology and examine the growth mechanism at the atomistic/molecular level [38]. Validation of the predicted crystal morphology (commonly carried out in a vacuum environment) is a complex and challenging process in which in an actual situation, the crystals are grown in an environment with the presence of solvents and additives [39-40]. Molecular structure of a crystal is packed in a unit cell as a building unit and heavily depending on intermolecular interaction such as hydrogen bond and van der Waals between the molecules and are the important parameters, which affect the crystal shape, and hence the degree of solubility [41]. The crystal morphology also has a significant impact on processing and product performances [42]. In most cases, the use of different solvents results in different crystal morphology, the polar solvent will form the elongated crystal morphology, while high packing density will form the needle-like and plate-like crystal [43-45].

The traditional method used to predict the crystal morphology is via a periodic bond chain (PBC) by Donnay Harker analysis, and the attachment energy calculation, $\mathrm{E}_{\text {att }}$ (AE model) [44]. Hartman and Bennema reported that the $E_{\text {att }}$ is related to the growth rate of the crystal [45]. Attachment energy is defined as the energy released upon the attachment of a slice with a $\mathrm{d}_{\text {hkl }}$ width of a growing crystal facet [42].

$\mathrm{E}_{\text {lat }}=\mathrm{E}_{\mathrm{att}}+\mathrm{E}_{\mathrm{sli}}$

where $E_{\text {lat }}$ is the lattice energy that is proportional to the crystal growth rate, hence the larger attachment energy will result in faster crystal facet growth, thus less morphologically important $[42,45-47]$. $\mathrm{E}_{\text {sli }}$ is the slice energy, which is the energy of a growth slice with the thickness $d_{\text {hkl }}$ surface of a growing crystal [45]. This calculation has been successfully used in a diverse range of contemporary applications such as the morphology prediction of pharmaceuticals [48], explosives [49], organic pigments [50], phases constituting kidney stones [51], and interpretation of inverse gas chromatography data [52]. This method also has proven to be useful in the prediction of the crystal morphology, which involves the anisotropic energies in the crystal unit cell [39,5354].

The exposed groups on the crystal facets play an important role when the crystal is in contact with external material such as the solvent. Exposure of a polar group will make the particular facet to be a polar facet, and vice versa [39]. The use of a polar solvent (or mixtures of them) on the polar crystal tends to shorten the crystal habit [44], as the solvent stops the growth of the fast-growing crystal.

In this study, NIC:COU cocrystal was synthesized with different feed molar ratios of 1:1, 1:2, and 2:1 using acetonitrile, and characterized. Acetonitrile is a common solvent used in the cocrystallization such as nicotinamide: 3-hydroxybenzoic acid (1:1) and pyrazinamide:2,5dihydroxybenzoic acid (1:1) cocrystals [55]. The use of acetonitrile mixture solvent also resulted in the formation of enthenzamide:gentisic acid cocrystal polymorphs [56]. This study also suggested the effect of combined molecular structures in the cocrystal on the solubility in ethanol and the bioactivity by an antioxidant study using DPPH assay. The solubility data is vital as it is an important physicochemical property that affects the bioavailability of the drug, while the changes in antioxidant activity were studied at different concentrations to determine the potential of the cocrystal towards health promotion as rendered by many dietary supplements. A molecular modeling technique was also carried out in this study for the morphology prediction of the NIC:COU (1:1) cocrystal and the examination of its surface chemistry.

\section{- EXPERIMENTAL SECTION}

\section{Materials}

Nicotinamide $\left(\mathrm{C}_{6} \mathrm{H}_{6} \mathrm{~N}_{2} \mathrm{O}, \mathrm{MW}=122.13 \mathrm{~g} / \mathrm{mol}\right.$, $>99.0 \%$ purity) was purchased from Across Organic, Belgium. p-Coumaric acid $\left(\mathrm{C}_{9} \mathrm{H}_{8} \mathrm{O}_{3}, \mathrm{MW}=164.05 \mathrm{~g} / \mathrm{mol}\right.$, 98.0\% purity) was purchased from Sigma Aldrich, UK. 2,2-diphenyl-1-picryl-hydrazyl-hydrate (DPPH) free radical $\left(\mathrm{C}_{18} \mathrm{H}_{12} \mathrm{~N}_{5} \mathrm{O}_{6}, \mathrm{MW}=394.32 \mathrm{~g} / \mathrm{mol}\right)$ used in the antioxidant test was purchased from Merck, Germany. 
The solvent, acetonitrile (99.9\% purity), and ethanol (HPLC purity > 99.9\%) were purchased from RCI Labscan, Thailand, and the DMSO- $\mathrm{d}_{6}(\geq 99.8 \%$ deuteration degree) used for the NMR analysis was purchased from Merck, Germany. All chemicals and solvents were used as received without further purification.

\section{Procedure}

\section{Preparation of cocrystal for characterization experiment}

Cocrystals used in the characterization experiments were prepared using a rotary evaporation method (RTV) (Rotavapor R-210, BUCHI, Switzerland), at $50^{\circ} \mathrm{C}, 100 \mathrm{~atm}$, and $100 \mathrm{rpm}$ speed. Three different feed molar ratios of NIC:COU were used, 1:1, 1:2, and 2:1 in acetonitrile to produce the NIC:COU cocrystal.

\section{Synthesis of NIC:COU (1:1) single crystal}

The single crystal of NIC:COU (1:1) was synthesized using slow evaporation method, in which an equimolar mixture of NIC $(122 \mathrm{mg}, 1 \mathrm{mmol})$ and COU $(164 \mathrm{mg}$, $1 \mathrm{mmol})$ was dissolved in acetonitrile $(10 \mathrm{~mL})$ at $50^{\circ} \mathrm{C}$ in a $20 \mathrm{~mL}$ vial. The solution was allowed to slowly evaporate in the vial with a perforated cap for four days until the crystal formed, harvested, and sent for crystal packing analysis using a single crystal X-ray diffractometer.

\section{Solid state characterization}

The cocrystals were characterized using differential scanning calorimeter (DSC), powder X-ray diffractometer (PXRD), Fourier transform infrared (FTIR) with attenuated total reflection (ATR) technique, and single crystal X-ray diffractometer (SCD).

The thermal analyses of the cocrystals were carried out using a Mettler Toledo differential scanning calorimeter (DSC). The temperature and cell constants were calibrated using indium. Samples (1-3 mg) were crimped in a nonhermetic aluminium DSC pan, heated from $30{ }^{\circ} \mathrm{C}$ to $300{ }^{\circ} \mathrm{C}$, with a heating rate of $10^{\circ} \mathrm{C} / \mathrm{min}$ on continuous nitrogen purge ( $40 \mathrm{~mL} / \mathrm{min})$.

Powder X-ray diffraction (PXRD) analyses were performed at ambient temperature using a Rigaku powder diffractometer with $\mathrm{Cu}-\mathrm{K}_{\alpha}$ radiation $(\lambda=1.5406 \AA)$ source. The tube voltage and amperage were set at $40 \mathrm{kV}$ and $40 \mathrm{~mA}$, respectively. The samples were analyzed in the range of $2 \theta$ from $5^{\circ}$ to $55^{\circ}$ with a scanning speed of $2 \% \mathrm{~min}$, and a step size of $0.02^{\circ}$. The diffraction patterns of the cocrystals were compared to the patterns of the pure compounds (controls).

A Perkin Elmer FTIR spectrophotometer using the ATR technique with Omnic software version 5.2 was used to determine the functional groups of NIC:COU cocrystals with a spectral resolution of $1 \mathrm{~cm}^{-1}$. The background spectrum composed of moisture and $\mathrm{CO}_{2}$ molecules was collected prior to the analyses, which will be automatically subtracted from the sample spectrum. The data were collected in the range of $4000-400 \mathrm{~cm}^{-1}$.

Single crystal X-ray diffraction data were collected using a Bruker D8 Quest diffractometer model using the graphite monochromatized $\mathrm{Mo}-\mathrm{K}_{\alpha}$ radiation $(\lambda=0.7107$ $\AA$ ) with APEX3 system. The crystal structure was refined using DOS-SHELXTL software, where all non-hydrogen atoms were refined anisotropically. The determination of intra and intermolecular hydrogen bonding was done using the PLATON software [57], and the preparation of figures was done using the MERCURY 3.8 software.

\section{Liquid state characterization}

The ${ }^{1} \mathrm{H}-\mathrm{NMR}$ analysis was used to verify the chemical structure of the NIC:COU (1:1) cocrystal, which will support the SCD data. The spectrum was collected using a Bruker NMR-600 MHz model. The analysis was carried out using DMSO- $\mathrm{d}_{6}$ solvent containing TMS.

The solubility of NIC, and NIC:COU (1:1) cocrystal was measured using the gravimetric method in ethanol from $10{ }^{\circ} \mathrm{C}$ to $60{ }^{\circ} \mathrm{C}$. An excess amount of sample was added to ethanol $(10 \mathrm{~mL})$ in a $50 \mathrm{~mL}$ jacketed glass vessel. The flask was placed in a water bath with a controlled temperature $\left( \pm 0.1^{\circ} \mathrm{C}\right)$ and continuously stirred for $24 \mathrm{~h}$. The solution was allowed to settle for $12 \mathrm{~h}$ before sampling. The supernatant was withdrawn using a syringe $(5 \mathrm{~mL})$, filtered, and placed in an evaporating dish (pre-weighed). The weight of the solution was recorded before drying in an oven at $50{ }^{\circ} \mathrm{C}$ for 4 days. The dried sample was then reweighed and recorded.

The antioxidant capacities of the samples were determined using a DPPH free radical scavenging assay. A fresh solution of DPPH $(0.1 \mathrm{mM})$ was prepared in ethanol. The samples were prepared in serial dilution 
from $1000 \mu \mathrm{M}$ to $2 \mu \mathrm{M}$ in ethanol. The DPPH solution $(10 \mu \mathrm{L})$ was added to the sample $(1 \mu \mathrm{L})$ and the respective blank $(1 \mu \mathrm{L})$. The samples were incubated in the dark for $30 \mathrm{~min}$. The absorbance of the samples after the incubation period was measured using a BMG LABTECH microplate reader at $517 \mathrm{~nm}$ [58]. The DPPH radical scavenging capacity was calculated using Eq. (2) [59-60]. DPPH radical scavenging capacity $(\%)=\frac{\mathrm{A}_{0}-\mathrm{A}_{1}}{\mathrm{~A}_{0}} \times 100 \%$

$\mathrm{A}_{0}$ and $\mathrm{A}_{1}$ correspond to the absorbance of antioxidant at $517 \mathrm{~nm}$ of the DPPH radical for the blank and the sample, respectively.

\section{Computational techniques}

The modeling of NIC:COU (1:1) cocrystal morphology was carried out using the Material Studio (MS) package, from Accelrys Inc., using the embedded modules and protocols in determining the atomic charges, lattice energy, and the prediction of the crystal growth morphology under vacuum environment. The force fields applied were Compass, Dreiding, and Universal. Compass is a force field with most of the parameters was derived based on the derivation of $a b$ initio calculation, while other parameters were fitted empirically. Dreiding force field with the application of the general force constants and geometry parameters [61] is widely applicable for simulation of biological, organic, and main-group inorganic molecules to determine the structures and dynamics. The dreiding force field is believed to be the most relevant force field available in MS for treating the organic molecules [47]. The Universal force field is acknowledged as a moderately accurate prediction for the geometries and conformational energies of organic molecules, some inorganics, and metal complexes [53].

\section{Atomic charges determination}

The atomic charges of the molecules of NIC:COU (1:1) cocrystal were calculated using the density functional theory (DFT) of the quantum mechanical code in the MS. DFT quantum code is an ab initio method with high accuracy in the estimation of the electronic properties of the atoms. Three types of atomic charges were used to determine the most suitable charges for the cocrystal, Mulliken, Hirshfeld, and electrostatic potential fitting (ESP). This was done by applying the DFT quantum mechanical code with a PW91 gradientcorrected functional correlation, an 'all electrons' core treatment, and the DNP basis set [53]. The calculated charges were then assigned to the molecules.

\section{Lattice energy determination and morphology prediction}

MS software was used to calculate the lattice energy and simulate the cocrystal morphology using the attachment energy (AE) summation method.

The protocols adopted for the morphology prediction of NIC:COU $(1: 1)$ cocrystal were as follows: The NIC:COU (1:1) cocrystal structure with CCDC deposition number of 1587901, the chemical name of 3(4-hydroxyphenyl)-prop-2-enoic acid pyridine-3carboxamide was obtained from the refined structure using DOS-SHELXTL software. The atomic charges were calculated using the methods described earlier, which then assigned to the molecules. The molecules were subjected to two stages of the minimization process, (1) the molecules in the unit cell were minimized while the conformations of the molecules were kept fixed, but the molecules were allowed to move within the crystal packing, and (2) the conformation of the molecules were relaxed in the unit cell, and the molecules were allowed to move during the minimization process. The predicted morphology of the cocrystal was calculated using the growth morphology module in the MS software with assigned atomic charges/force fields pairs. Each set of atomic charges/force field produced different crystal morphology, which was then compared with the experimental cocrystal morphology for validation purposes.

\section{- RESULTS AND DISCUSSION}

\section{Differential Scanning Calorimetry (DSC)}

Fig. 2 shows the DSC thermogram of the NIC, COU, and the NIC:COU mixtures with the feed molar ratios of 1:1, 1:2, and 2:1. NIC showed a sharp endotherm at $129.94{ }^{\circ} \mathrm{C}$ without any phase transformation, while $\mathrm{COU}$ melted at a higher temperature of $221.62{ }^{\circ} \mathrm{C}$ with a 


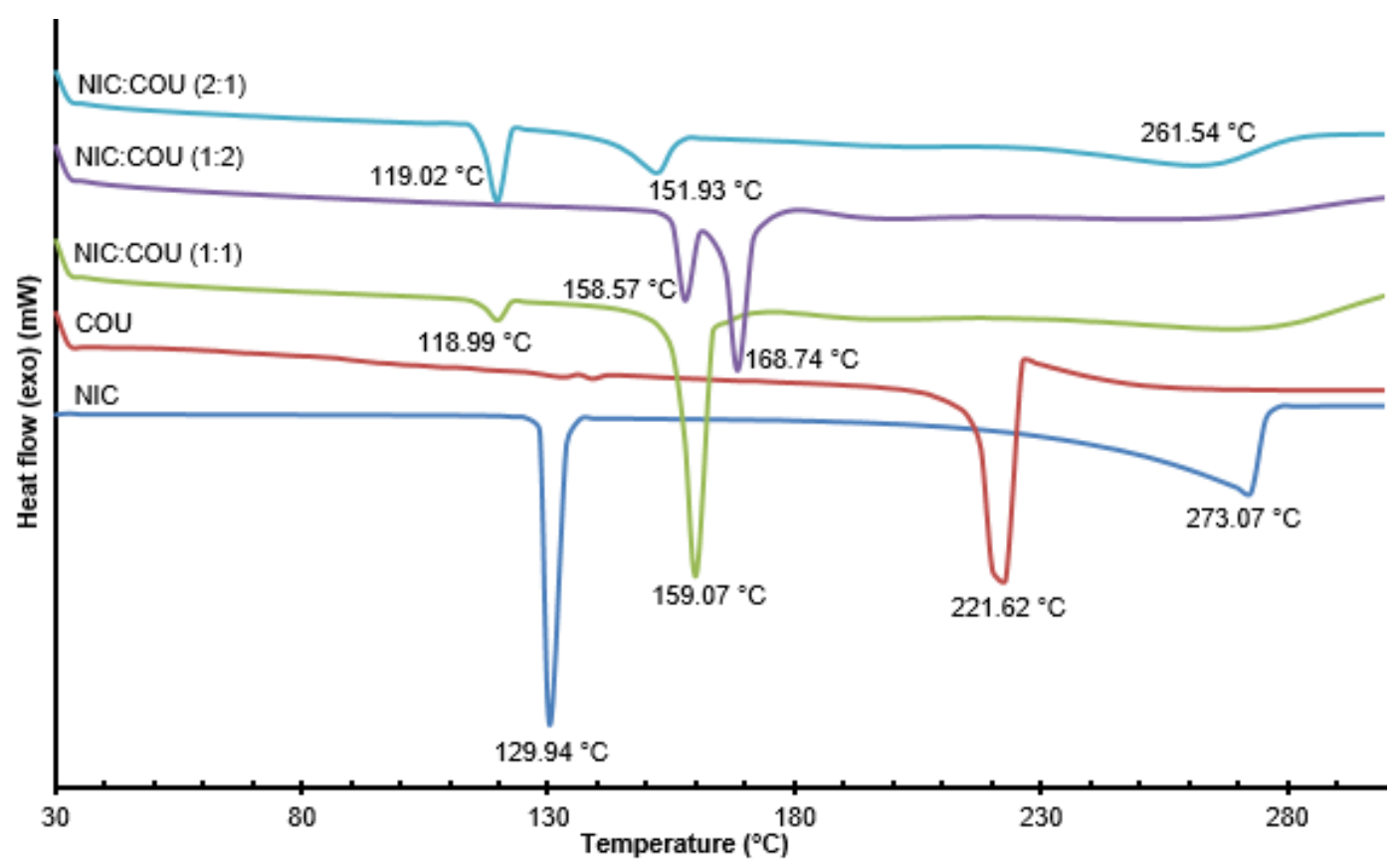

Fig 2. DSC thermogram of NIC, COU, and NIC:COU cocrystals

single endotherm upon heating. The NIC:COU (1:1) mixture melts at $159.07^{\circ} \mathrm{C}$, which is in between NIC and COU melting temperatures. Another minor melting event observed for $1: 1$ cocrystal is at $118.99^{\circ} \mathrm{C}$ with very low intensity. A cocrystal is commonly identified from a DSC thermogram in which the melting temperature of the cocrystal is usually located in between or below of the parent compounds $[5,22,62]$, which was observed in this work. The melting temperature of the NIC:COU (1:1) cocrystal produced in this work is in between the melting temperatures of the polymorphic forms of the NIC:COU (1:1) cocrystals, which were $158^{\circ} \mathrm{C}($ Form 2$)$ and $160{ }^{\circ} \mathrm{C}$ (Form 3) [7]. There was no melting event recorded in the same research [7] for $118.99^{\circ} \mathrm{C}$, which perhaps indicating the development of a new crystal phase of the NIC:COU (1:1) cocrystal, discovered in this study. The other two polymorphs of NIC:COU cocrystal were recorded by the previous researcher [7] named Form 1, and Form 4 with melting temperatures of $154^{\circ} \mathrm{C}$ and $174{ }^{\circ} \mathrm{C}$, respectively.

The NIC:COU (1:2) mixture shows a phase transformation with two melting temperatures at $158.57^{\circ} \mathrm{C}$, and $168.74{ }^{\circ} \mathrm{C}$ respectively. The first melting temperature is in agreement with the Form 2 polymorph of the NIC:COU cocrystal with a melting point of $158^{\circ} \mathrm{C}$ [7]. The melting temperature at $168.74^{\circ} \mathrm{C}$ is also suspected as a new crystal phase of NIC:COU (1:2) cocrystal, since there was no data recorded. There is no melting event of Form 4 NIC:COU cocrystal at $174{ }^{\circ} \mathrm{C}$ [7], which has a similar feed molar ratio, signifying that the use of a different solvent is able to form different characteristics of the crystal [43].

The NIC:COU (2:1) mixture shows a much similar pattern as NIC:COU (1:1) cocrystal, with the obvious difference, observed in the intensity of the minor melting peak in NIC:COU (1:1) mixture at the comparable melting temperature of $119.02{ }^{\circ} \mathrm{C}$. This confirmed the development of a new crystal phase of the NIC:COU. The second melting temperature located at $151.93{ }^{\circ} \mathrm{C}$, which likely to form Form 1 NIC:COU cocrystal, with a melting temperature of $154^{\circ} \mathrm{C}$ [7]. The differences in melting temperatures of the synthesized cocrystals as compared to the parent compounds reflect the changes in the crystal lattice, intermolecular interaction, molecular symmetry, or conformational degree of freedom, which are responsible for the change in physicochemical properties of the cocrystals [2].

\section{Powder X-ray Diffraction (PXRD)}

The PXRD patterns of NIC, COU, and the NIC:COU cocrystals are presented in Fig. 3. The 
comparison between diffractograms of NIC:COU cocrystals with NIC and COU revealed the feasible interaction between NIC and COU, which anticipated the formation of new crystalline phases due to the additional peaks. The new major peaks observed in all feed molar ratios of NIC:COU $(1: 1,1: 2$, and $2: 1)$ are at $2 \theta$ of $15.62^{\circ}$, $16.66^{\circ}$. The development of a new diffraction peak in NIC:COU (1:1) cocrystal at $2 \theta$ of $24.66^{\circ}$ confirmed the formation of the pure cocrystal. On the other hand, NIC:COU mixtures with 1:2 and 2:1 molar ratios revealed the formation of the cocrystal with the mixture of the pure compounds since most of the diffraction peaks of the pure compounds are observed.

\section{Fourier Transform Infrared (FTIR)}

The molecular interaction between NIC and COU was analyzed using FTIR spectroscopy with the ATR method. Fig. 4 shows the FTIR spectra of the NIC:COU cocrystals stacked with the pure compounds, NIC, and COU. The regions with potential functional groups which are able to form the hydrogen bond are observed, which are the pyridine ring and amide groups of NIC, and carboxylic acid and phenol groups of COU.

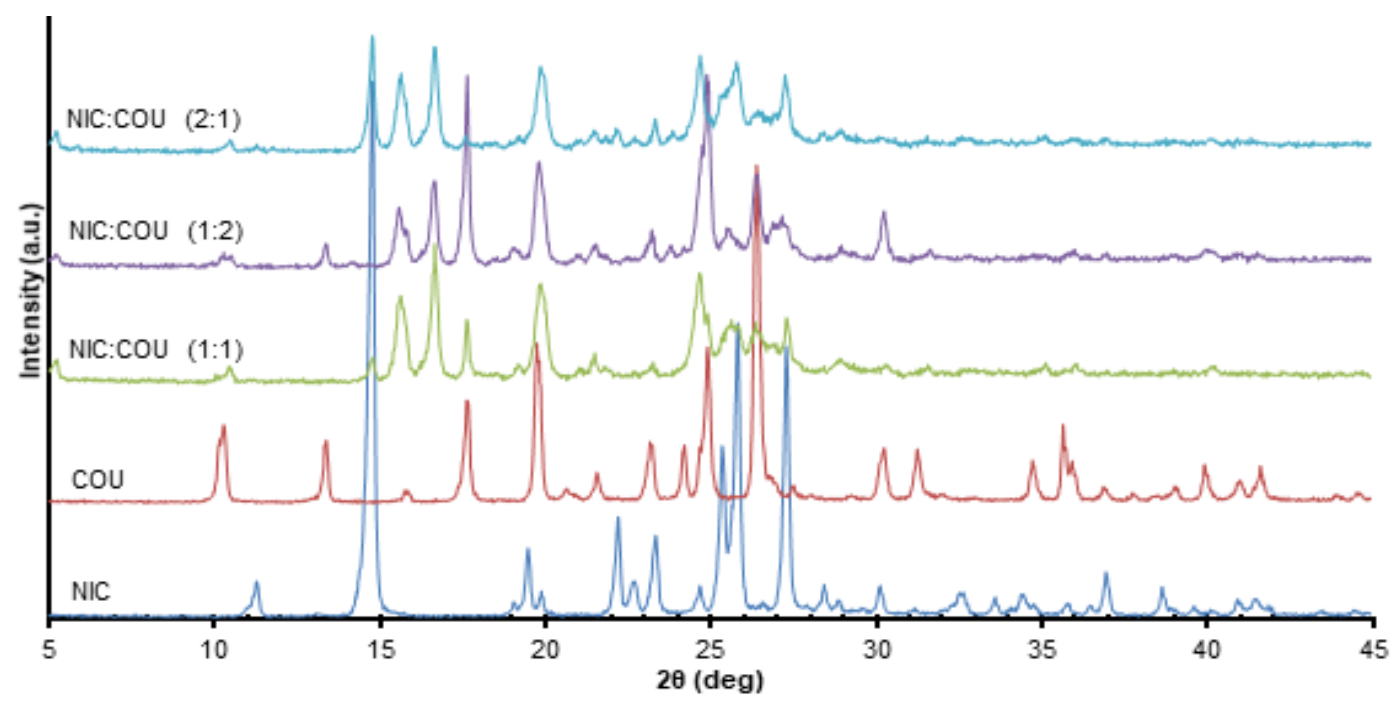

Fig 3. PXRD patterns of NIC, COU, and NIC:COU cocrystals

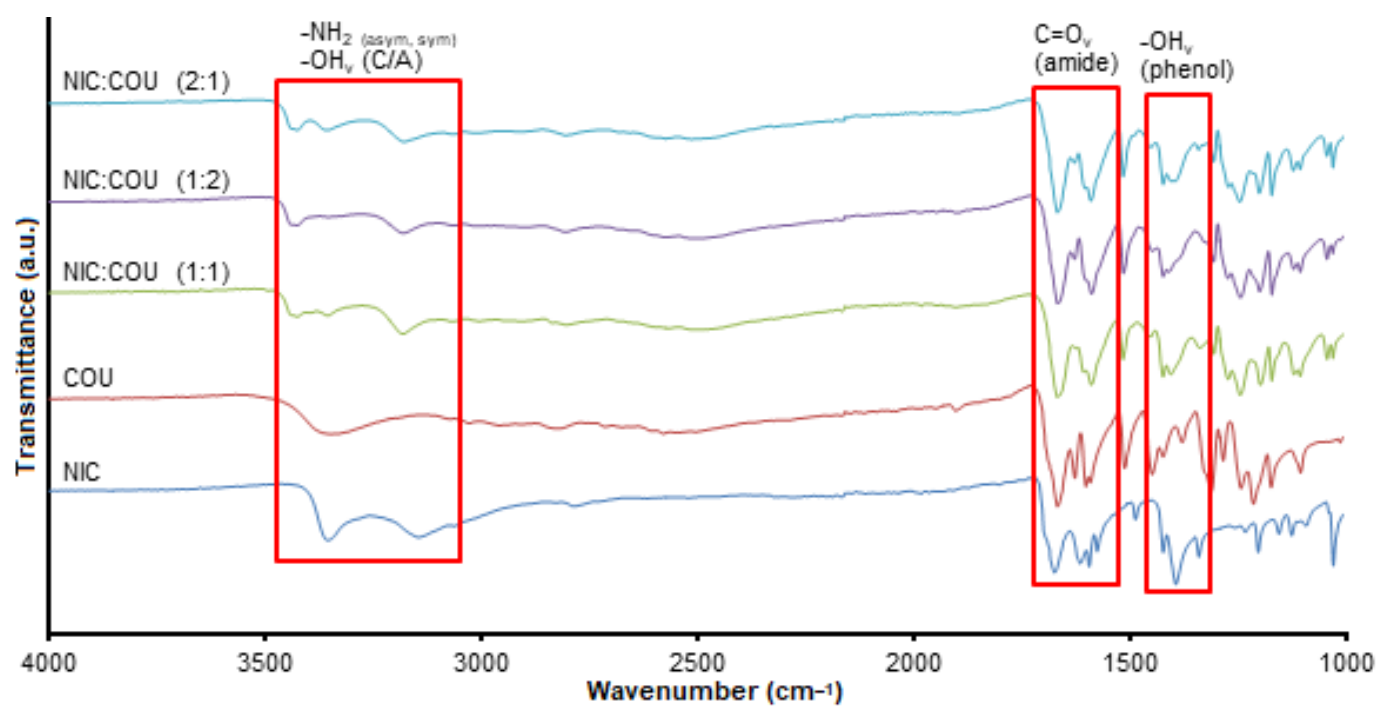

Fig 4. FTIR spectra of NIC, COU, and NIC:COU cocrystals 
NIC:COU (1:1) cocrystal shows that the $\mathrm{C}=\mathrm{O}$ stretching of NIC is shifted from $1674 \mathrm{~cm}^{-1}$ to $1667 \mathrm{~cm}^{-1}$, which demonstrates the formation of hydrogen bonding on the oxygen which acts as hydrogen bond acceptor. The stretching of asymmetrical and symmetrical $-\mathrm{NH}_{2}$ amide of NIC is shifted to higher wavenumber from $3354 \mathrm{~cm}^{-1}$ and $3145 \mathrm{~cm}^{-1}$ to $3355 \mathrm{~cm}^{-1}$ and $3181 \mathrm{~cm}^{-1}$ respectively. The shifts of these bands show the formation of a new phase due to the intermolecular hydrogen bonding from the two proton donors of the $-\mathrm{NH}_{2}$ group. This is supported by the bending vibration of $-\mathrm{NH}$ band [4], which also shifted from $1614 \mathrm{~cm}^{-1}$ to $1607 \mathrm{~cm}^{-1}$. The stretching vibration of the nitrogen atom of the pyridine ring of NIC at $1393 \mathrm{~cm}^{-1}$ is shifted to $1404 \mathrm{~cm}^{-1}$ confirmed the utilization of the nitrogen as the best hydrogen acceptor group [24]. The additional peak at $3425 \mathrm{~cm}^{-1}$ shows the involvement of the acidic proton of COU in the formation of hydrogen bonding with NIC. The band observed at $1900 \mathrm{~cm}^{-1}$ attributes to the additional $\mathrm{O}-\mathrm{H} \cdots \mathrm{N}$ hydrogen bonds [7] present in the cocrystal. The $-\mathrm{OH}$ stretching vibration of phenol is shifted from $1378 \mathrm{~cm}^{-1}$ to $1336 \mathrm{~cm}^{-1}$ explains the participation of the $-\mathrm{OH}$ group in the formation of hydrogen bonding.

Due to the fact of different crystal phases produced as discussed in the previous sections, the shifting of vibration peaks for NIC:COU cocrystals with 1:2 and 2:1 feed molar ratios were also analyzed successfully. In NIC:COU (1:2) cocrystal, the stretching vibrations of $\mathrm{C}=\mathrm{O}$ amide and pyridine of NIC are shifted to the same wavenumber as NIC:COU $(1: 1)$ cocrystal at $1667 \mathrm{~cm}^{-1}$, and $1404 \mathrm{~cm}^{-1}$ respectively. This confirmed that the same hydrogen bonding interaction pattern occurs in the NIC:COU (1:2) cocrystal. For $-\mathrm{NH}_{2}$ stretching vibration, only the symmetrical band is observed at $3178 \mathrm{~cm}^{-1}$, and the bending vibration of $-\mathrm{NH}$ is shifted to $1627 \mathrm{~cm}^{-1}$. An additional peak at $3426 \mathrm{~cm}^{-1}$ is due to the formation of hydrogen bonding from the acidic proton of COU, and the peak at $1895 \mathrm{~cm}^{-1}$ corresponds to the formation of the $\mathrm{O}-\mathrm{H} \cdot \cdots \mathrm{N}$ hydrogen bond. The stretching vibration peak of $-\mathrm{OH}$ phenol is also diminished which is another characteristic of the hydrogen bonding behavior of the

\section{NIC:COU (1:2) cocrystal.}

The 2:1 feed molar ratio of NIC:COU cocrystal also shows the $\mathrm{C}=\mathrm{O}$ amide stretching vibration at the same wavenumber as NIC:COU cocrystal with 1:1 and 1:2 feed molar ratios at $1667 \mathrm{~cm}^{-1}$. The asymmetric and symmetric stretching of $-\mathrm{NH}_{2}$ bands are shifted to $3356 \mathrm{~cm}^{-1}$ and $3177 \mathrm{~cm}^{-1}$ respectively, while no $-\mathrm{NH}$ bending vibration observed in the spectrum. The pyridine stretching vibration is shifted to $1394 \mathrm{~cm}^{-1}$, and no peak observed for the $\mathrm{O}-\mathrm{H} \cdots \mathrm{N}$ hydrogen bond formation. The acidic proton stretching vibration is shifted to $3426 \mathrm{~cm}^{-1}$, and $-\mathrm{OH}$ phenol stretching vibration is shifted to $1340 \mathrm{~cm}^{-1}$. These differences in the FTIR spectrum again confirmed the formation of different crystal phases with different hydrogen-bonding interactions. The summary of the differences in the vibration bands observed in the NIC:COU cocrystals can be found in Supplementary Material, section S1.

\section{Nuclear Magnetic Resonance (NMR)}

${ }^{1} \mathrm{H}-\mathrm{NMR}$ was carried out to confirm the chemical structure of the synthesized cocrystal supporting the data from single crystal X-ray diffraction (SCD) analysis. The chemical structures of NIC and COU were confirmed by comparing the ${ }^{1} \mathrm{H}-\mathrm{NMR}$ signals with previous researchers [63-64]. The ${ }^{1} \mathrm{H}-\mathrm{NMR}$ signals of the NIC:COU (1:1) cocrystal are consistent with the signals of NIC and COU with a slight difference or no difference in terms of the chemical shift. The integration of NMR signals of the cocrystals reveals the same number of protons with the results from SCD analysis, which will be discussed in the next section. Table 1 shows the chemical shifts with the multiplicity of the NIC:COU (1:1) cocrystal in comparison with NIC and COU. The signal from NIC at $7.48 \mathrm{ppm}(\mathrm{m}, 1 \mathrm{H})$ overlaps with a signal from $\mathrm{COU}$ at $7.49 \mathrm{ppm}(\mathrm{m}, 3 \mathrm{H})$ results in a multiplet signal with four protons. The use of DMSO- $\mathrm{d}_{6}$ as the NMR solvent was able to reveal the proton signal of the $-\mathrm{OH}$ (carboxylic acid and phenol) of COU, which is observed downfield, at $9.96 \mathrm{pm}$, and $12.12 \mathrm{ppm}$ due to the high polarity of the $-\mathrm{OH}$ groups. 
Table 1. The comparison of chemical shifts between NIC:COU (1:1) cocrystal with NIC and COU

\begin{tabular}{cccccc}
\hline \multicolumn{2}{c}{ Nicotinamide (NIC) } & \multicolumn{2}{c}{$p$-Coumaric acid (COU) } & \multicolumn{2}{c}{ NIC:COU (1:1) } \\
\hline Chemical shift, ppm $(\delta)$ & Multiplicity & Chemical shift, ppm $(\delta)$ & Multiplicity & Chemical shift, ppm $(\delta)$ & Multiplicity \\
\hline & & 6.26 & $\mathrm{~d}$ & 6.26 & $\mathrm{~d}$ \\
7.48 & & 6.77 & $\mathrm{~d}$ & 6.77 & $\mathrm{~d}$ \\
& $\mathrm{~m}$ & & & 7.47 & $\mathrm{~m}$ \\
7.59 & & & $\mathrm{~m}$ & 7.47 & $\mathrm{~m}$ \\
8.15 & $\mathrm{~s}$ & & & 7.59 & $\mathrm{~s}$ \\
8.18 & $\mathrm{~s}$ & & & 8.15 & $\mathrm{~s}$ \\
8.68 & $\mathrm{~d}$ & & & 8.18 & $\mathrm{~d}$ \\
9.01 & $\mathrm{~d}$ & & $\mathrm{~s}$ & 8.68 & $\mathrm{~d}$ \\
& $\mathrm{~s}$ & 9.96 & $\mathrm{~s}$ & 9.01 & $\mathrm{~s}$ \\
& & 12.12 & & & \\
& & & & & $\mathrm{~s}$ \\
\hline
\end{tabular}

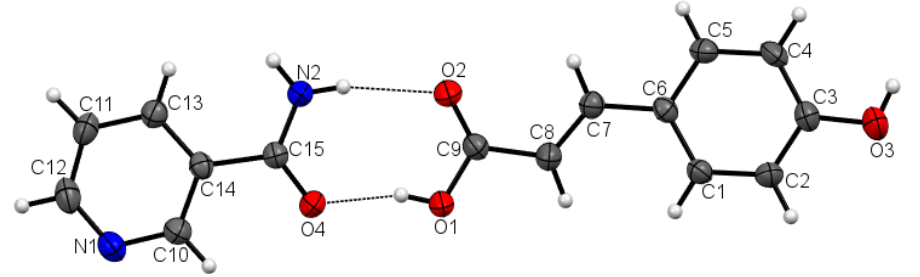

Fig 5. ORTEP drawing of NIC:COU (1:1) cocrystal with the atom labeling in the asymmetric unit

\section{Crystallography Analysis of NIC:COU (1:1) Cocrystal}

Fig. 5 and Table 2 show the ORTEP drawing of the asymmetric unit of NIC:COU (1:1) cocrystal and the crystallographic data of the cocrystal, respectively.

The NIC:COU (1:1) cocrystal was synthesized using the slow evaporation method with acetonitrile. The interaction is expected to occur between the nitrogen atom on the pyridine ring of NIC and acid group of COU, amide-amide, and amide-acid [11], and phenol-pyridine $[32,36]$ hydrogen bonding linkages. The assessment of the asymmetric unit of the cocrystal shows that the 1:1 molecule crystallizes in a monoclinic crystal lattice with $\mathrm{P} 2_{1} / \mathrm{c}$ space group, similar to the published Form 1 NIC:COU (1:1) cocrystal structure [7]. The synthesized cocrystal revealed greater stability with a higher melting temperature compared to the published cocrystal. All bond lengths and angles for both independent molecules are within the expected values, tabulated in the Supplementary Material, section S1, S2, and S3, respectively. The crystal structure data comparison between the synthesized cocrystal with the published cocrystal are presented in Table 4 .

Table 2. Crystal data and structure refinement parameters of NIC:COU (1:1) cocrystal

\begin{tabular}{|c|c|}
\hline Empirical formula & $\mathrm{C}_{15} \mathrm{H}_{14} \mathrm{~N}_{2} \mathrm{O}_{4}$ \\
\hline Moiety formula & $\mathrm{C}_{6} \mathrm{H}_{62} \mathrm{O}, \mathrm{C}_{9} \mathrm{H}_{8} \mathrm{O}_{3}$ \\
\hline Formula weight $(\mathrm{g} / \mathrm{mol})$ & 286.28 \\
\hline Crystal system & monoclinic \\
\hline Space group & $\mathrm{P} 22_{1} / \mathrm{c}$ \\
\hline R1-value & 0.0751 \\
\hline Crystal size $\left(\mathrm{mm}^{3}\right)$ & $0.40 \times 0.50 \times 0.50$ \\
\hline a (̊̊) & $15.675(2)$ \\
\hline b $(\AA)$ & $6.3538(8)$ \\
\hline$c(\AA)$ & $14.433(2)$ \\
\hline$\alpha\left(^{\circ}\right)$ & 90 \\
\hline$\beta\left(^{\circ}\right)$ & $106.945(4)$ \\
\hline$\Upsilon\left({ }^{\circ}\right)$ & 90 \\
\hline $\mathrm{V}\left(\hat{\mathrm{A}}^{3}\right)$ & $1375.1(3)$ \\
\hline $\mathrm{Z}$ & 4 \\
\hline $\mathrm{D}_{\mathrm{c}}\left(\mathrm{g} \mathrm{cm}^{-3}\right)$ & $1.3828(3)$ \\
\hline$\mu\left(\mathrm{mm}^{-1}\right)$ & 0.102 \\
\hline$\lambda(\hat{A})$ & 0.7107 \\
\hline $\mathrm{T}(\mathrm{K})$ & $273(2)$ \\
\hline $\mathrm{F}(000)$ & 600 \\
\hline $2 \theta$ range $\left(^{\circ}\right)$ & $2.951-28.352$ \\
\hline Reflection collected/unique & $28920 / 3404[R(\mathrm{int})=0.0806]$ \\
\hline Data/parameters/restraints & $3404 / 195 / 1$ \\
\hline Goodness of fit & 1.086 \\
\hline Data collection & Bruker APEX2 \\
\hline Data reduction & Bruker SAINT \\
\hline Structure solution & SHELXS-97 (Sheldrick 2008) \\
\hline Structure refinement & SHELXL-2013 (Sheldrick 2013) \\
\hline
\end{tabular}


The crystal structure shows no intramolecular interaction, no $\pi-\pi$ stacking interaction, and no proton transfer from $-\mathrm{COOH}$ group of COU. The crystal structure is stabilized by intermolecular hydrogenbonding interactions O1-H1A...O 4 (2.554 $\AA$ ), N2-

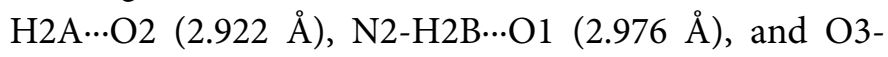
H3 …N1 (2.713 $\AA)$. These intermolecular interactions are in good agreement with the FTIR result, which anticipated in the formation of the cocrystal. The hydrogen bond geometries were summarized in Table 3 . Based on the hydrogen bonding interaction observed, the homomeric $\mathrm{R}_{2}^{2}(8)$ ring is formed between a pair of $-\mathrm{NH}$ amide hydrogen-bonded to the oxygen of carbonyl group linking the tetrameric hydrogen-bonded rings into an infinite ribbon.

The hydrogen bonding interaction pattern in NIC:COU (1:1) cocrystal was consistent with Form 1
NIC:COU (1:1) cocrystal synthesized by the previous researcher [7]. Although the hydrogen bonding interaction patterns are similar, the hydrogen bonding geometry of the synthesized cocrystal in this study are off-plane for N2-H2B $\cdots \mathrm{O} 1$, and $\mathrm{O} 3-\mathrm{H} 3 \cdots \mathrm{N} 1$ compared to the reported data. Bevill et al. [7] revealed a more planar geometry of $\mathrm{N} 2-\mathrm{H} 2 \mathrm{~B} \cdots \mathrm{O} 1$, and $\mathrm{O} 3-\mathrm{H} 3 \cdots \mathrm{N} 1$ hydrogen bonding interactions with $161.5^{\circ}$, and $164^{\circ}$, compared to the synthesized NIC:COU $(1: 1)$ cocrystal in this study with $153^{\circ}$, and $139^{\circ}$ respectively. This supports the difference in the melting point of the synthesized cocrystal in this study with the cocrystals synthesized by Bevill et al. [7], which reflects the different solvent used for the cocrystal synthesis is able to change the properties of the cocrystal. The change of the properties of the cocrystal is crucial where it indicates the bioavailability and the stability of the compound.

Table 3. Hydrogen bond geometry $\left(\AA\right.$ and $\left.^{\circ}\right)$ in NIC:COU (1:1) cocrystal

\begin{tabular}{lllll}
\hline $\mathrm{D}-\mathrm{H} \cdots \mathrm{A}$ & $\mathrm{D}(\mathrm{D}-\mathrm{H})$ & $\mathrm{d}(\mathrm{H} \cdots \mathrm{A})$ & $\mathrm{D}(\mathrm{D} \cdots \mathrm{A})$ & $\angle \mathrm{D}-\mathrm{H} \cdots \mathrm{A}$ \\
\hline $\mathrm{O} 1-\mathrm{H} 1 \mathrm{~A} \cdots \mathrm{O} 4$ & $0.82(3)$ & $1.76(3)$ & $2.554(3)$ & $162(3)$ \\
$\mathrm{N} 2-\mathrm{H} 2 \mathrm{~A} \cdots \mathrm{O} 2$ & 0.86 & 2.08 & $2.922(3)$ & 167 \\
$\mathrm{~N} 2-\mathrm{H} 2 \mathrm{~B} \cdots \mathrm{O} 1$ & 0.86 & 2.18 & $2.976(3)$ & 153 \\
$\mathrm{O} 3-\mathrm{H} 3 \cdots \mathrm{N} 1$ & 0.82 & 2.04 & $2.713(3)$ & 139 \\
\hline
\end{tabular}

Table 4. Comparison between the synthesized NIC:COU (1:1) cocrystal with reported data

\begin{tabular}{lccc}
\hline & Experiment, & \multicolumn{2}{c}{ Literature [7] } \\
\cline { 3 - 4 } & NIC:COU $(1: 1)$ & Form 1 & Form 3 \\
\hline Melting temp $\left({ }^{\circ} \mathrm{C}\right)$ & 159.07 & 154 & 160 \\
Empirical formula & $\mathrm{C}_{15} \mathrm{H}_{14} \mathrm{~N}_{2} \mathrm{O}_{4}$ & $\mathrm{C}_{15} \mathrm{H}_{14} \mathrm{~N}_{2} \mathrm{O}_{4}$ & $\mathrm{C}_{15} \mathrm{H}_{14} \mathrm{~N}_{2} \mathrm{O}_{4}$ \\
Crystal habit & gold, plate & colorless, plate & colorless, rod \\
Crystal system & monoclinic & monoclinic & monoclinic \\
Space group, $\mathrm{Z}$ & $\mathrm{P} 2{ }_{1} / \mathrm{c}, 4$ & $\mathrm{P} 2{ }_{1} / \mathrm{c}, 4$ & $\mathrm{C} 2 / \mathrm{c}, 16$ \\
$\mathrm{a}(\AA)$ & $15.675(2)$ & $15.5106(10)$ & $40.076(2)$ \\
$\mathrm{b}(\AA)$ & $6.3538(8)$ & $6.2871(4)$ & $7.1979(12)$ \\
$\mathrm{c}(\AA)$ & $14.433(2)$ & $14.1238(10)$ & $22.2876(12)$ \\
$\beta\left({ }^{\circ}\right)$ & $106.945(4)$ & $106.086(3)$ & $122.479(2)$ \\
$\mathrm{Volume}\left(\AA^{3}\right)$ & $1375.1(3)$ & $1323.38(15)$ & $5423.5(5)$ \\
$\mathrm{D}_{\mathrm{c}}\left(\mathrm{g} / \mathrm{cm}^{3}\right)$ & $1.3828(3)$ & 1.437 & 1.402 \\
$\mathrm{~T}(\mathrm{~K})$ & $273(2)$ & $120(2)$ & $120(2)$ \\
$\mu\left(\mathrm{mm}^{-1}\right)$ & 0.102 & 0.106 & 0.103 \\
$\mathrm{~F}(000)$ & 600 & 600 & 2400 \\
$\theta$ range $\left({ }^{\circ}\right)$ & $2.951-28.352$ & $2.73-32.58$ & $1.83-31.00$ \\
$\mathrm{R}-$ int & 0.0806 & 0.028 & 0.041 \\
$\mathrm{R}_{1}$ & 0.0751 & 0.0461 & 0.0537 \\
\hline
\end{tabular}




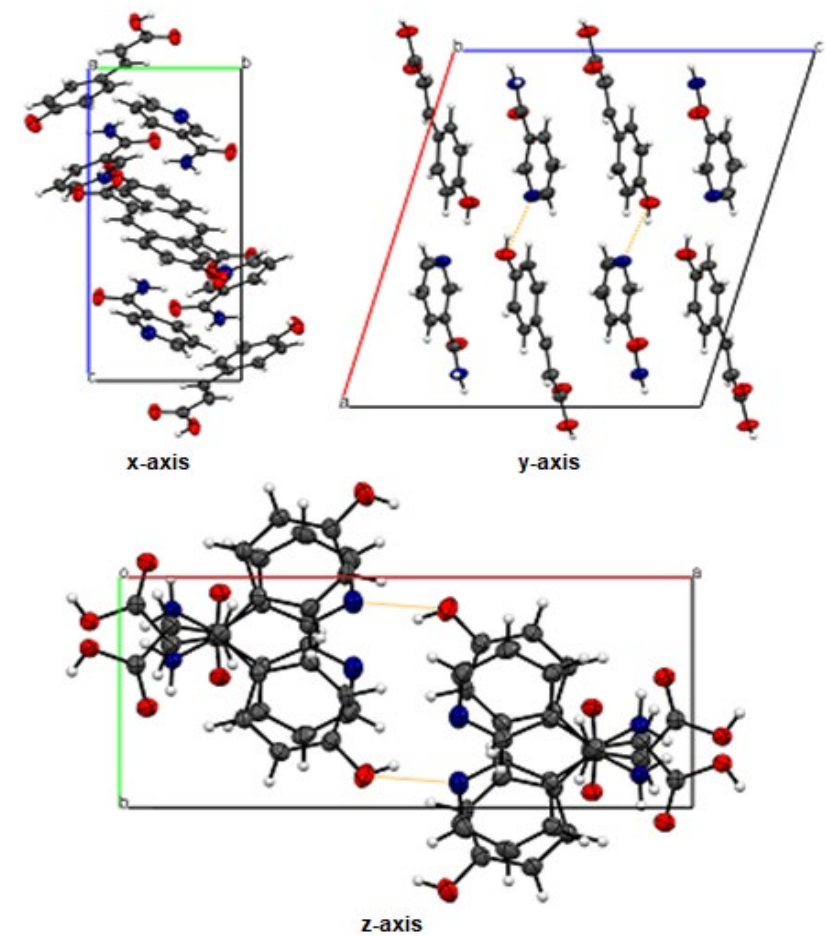

Fig 6. The crystal packing of NIC:COU (1:1) cocrystal

The crystal packing of NIC:COU (1:1) cocrystal from the $x, y$, and $z$ views is illustrated in Fig. 6 . The crystal lattice of NIC:COU (1:1) cocrystal is composed of the NIC and COU molecules alternately aligned with head to head stacking motif in the crystal lattice, observed from the yaxis. The differences in the molecular orientation are due to the non-centrosymmetric properties, differences in the hydrogen bonding patterns between the NIC and COU molecules, and also between the asymmetric pairs in the crystal lattice. The alignment of molecules and interaction between molecules in the crystal packing have a significant impact on the morphology of the crystal [41], which will be discussed in the crystal morphology prediction section.

\section{Intermolecular Assessment using Molecular Modelling Technique}

Table 5 shows the calculated lattice energy corresponds to the charge sets and force fields applied. The lattice energy was observed to be highly reliant on the charge set/force field applied. The lattice energy varies from $-110.874 \mathrm{kcal} / \mathrm{mol}$ (Hirshfeld/Compass) to -292.740 $\mathrm{kcal} / \mathrm{mol}$ (ESP/Compass). The $-\mathrm{NH}_{2}$ and $-\mathrm{COOH}$ groups undoubtedly contribute to the lattice energy value due to their participation in the hydrogen bonding formation within the crystal lattice [47]. The use of ESP charge results in the strong electrostatic interaction between the positive oxygen atom of $\mathrm{OH}$ in $\mathrm{COU}$ and the negative regions of the NIC. Similar trend was observed between 2,4,5,8,10,12-hexanitro-2,4,6,8,10,12-hexaazaisowurtzitane (CL-20) and trinitrotoluene (TNT) [65]. Thus, it can be concluded that ESP/Compass pair forms the strongest hydrogen bonding interaction, while the Hirshfeld/Compass pair forms the weakest hydrogen bonding interaction between the NIC and COU molecules in the crystal lattice.

\section{Morphological Prediction of NIC:COU (1:1) Cocrystal}

Fig. 7(a) shows the crystal shape of NIC:COU (1:1) cocrystal grown from acetonitrile, and Fig. 7 (b) shows the

Table 5. Lattice energies (kcal/mol) of NIC:COU (1:1) cocrystal computed using different charge sets and force fields

\begin{tabular}{ccc}
\hline Force field & Type of charge & $\mathrm{E}_{\text {latt }}(\mathrm{kcal} / \mathrm{mol})$ \\
\hline Compass & Mulliken & -247.403 \\
& Hirshfeld & -110.874 \\
& ESP & -292.740 \\
Universal & Mulliken & -210.824 \\
& Hirshfeld & -146.484 \\
& ESP & -226.753 \\
Dreiding & Mulliken & -282.145 \\
& Hirshfeld & -194.309 \\
& ESP & -271.440 \\
\hline
\end{tabular}

(a)

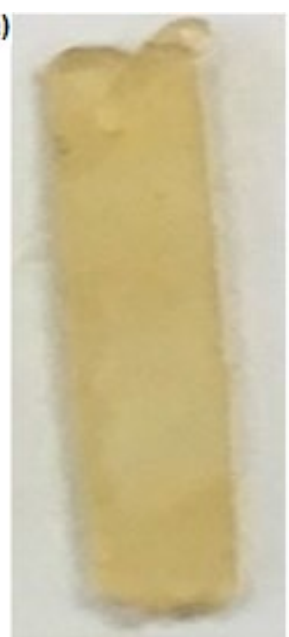

(b)

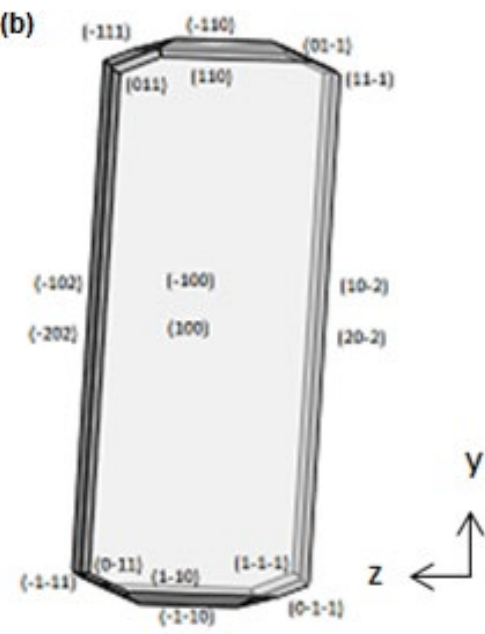

Fig 7. (a) NIC:COU (1:1) cocrystal grown in acetonitrile and (b) simulated NIC:COU (1:1) crystal morphology, predicted using Dreiding force field and ESP charge set 
predicted NIC:COU (1:1) cocrystal morphology using MS with AE method. The most acceptable morphology was accomplished using ESP charge set with Dreiding force field $\left(\mathrm{E}_{\text {latt }}=-271.440 \mathrm{kcal} / \mathrm{mol}\right)$ with similar predicted crystal shape with the experimental morphology. The predicted crystal morphology produces 18 crystal facets with elongated (along the y-axis) octagonal shape with the dominant facets of (100) and (-100). The long and thin sides comprise of (10-2), (20-2), (-102), and (-202) facets, while the top and bottom sides of the crystal composed of (110), (-110), (1-10), and (-1-10) facets. The edges of the crystal are bounded with (11-1), (-111), (-1-11), (1-1-1), (011), (01-1), (0-11), and (0-1-1). The published NIC:COU (1:1) cocrystal [7] simulated with similar force field/charge set pair (Dreiding/ESP) resulted in lower lattice energy of $-270.739 \mathrm{kcal} / \mathrm{mol}$, indicating the similar crystal structure with the same lattice energy.

The distribution of lattice energy was calculated using Eq. (1) is presented in Table 6. The dominant facet of (100), with its symmetry $(-100)$ facet has the minimum attachment energy of $-22.020 \mathrm{kcal} / \mathrm{mol}(8.112 \%)$, the largest $d_{100}$ of $15.915 \AA$, and the largest total facet area of $66.942 \%$, thus being the slowest growing rate face with high stability (Fig. 8(a)). The (100) facets were constructed with the COU, and NIC molecules alternatingly positioned, making every layer downward from the surface. The small crystal facet results with a higher growth rate, thus small slice energy, which makes (11-1) facet to be the least morphologically important crystal facet $[47,53]$.

The molecular packing of each NIC:COU (1:1) cocrystal facets are presented in Fig. 8(a-j). The molecular packing of NIC:COU (1:1) cocrystal facets reveal the hydrogen bonding interactions mainly occur at the amide group of NIC and the carboxylic acid group of COU. Most of the crystal facets show the open and rough surface topographies with large voids [39], except for the (20-2) facet, which forms a flat and smooth surface. In most cases, the crystal facet with flat and smooth surface results in a slow growth rate compared to the rough surface [66]. The slow growth rate crystal facet may also be due to the preferential adsorption of solvent molecules, as the growth kinetics is transferred to the polar surface $[53,66]$.

It was observed that $\mathrm{NH}_{2},-\mathrm{COOH}$, and $-\mathrm{OH}$ (phenol) groups are exposed on most of the crystal facets. The exposed group may affect the polarities of the crystal facet, which then affects the interaction with the solvent [39-40]. The crystal facet with exposed oxygen atoms (high polarity) will contribute to the high electrostatic energy for the particular facets [53]. The assessment of (20-2) facet with its symmetry (Fig. 8(c) and (d)) also shows significant conformational difference [53] (shown in red circle), which results in polar crystal facets.

Since the acidic proton is the best hydrogen bond donor, while the nitrogen atom of the pyridine ring is the best hydrogen bond acceptor, it was suggested that the facets exposed with these groups are ready to interact first with the solvent. Since the acetonitrile is a polar aprotic solvent, the (100) facet with exposed polar $-\mathrm{OH}$ groups hinders the growth of the facet resulting in larger a surface area. The (100), (1-10), (11-1), (1-1-1), (011), and (01-1) facets with exposed best hydrogen bond donor groups are expected to form the strongest hydrogen bond with the external compounds. It was also observed that the non-aggregated molecular arrangement patterns as (100) and (202) facets result with

Table 6. The distribution of attachment and slice energies for the NIC:COU (1:1) cocrystal facets, calculated using Eq. (1)

\begin{tabular}{cccccccc}
\hline Facet & Multiplicity & d-spacing & \multicolumn{2}{c}{ Attachment energy } & \multicolumn{2}{c}{ Slice energy } & \multirow{2}{*}{$\begin{array}{c}\text { Total facet } \\
\text { area }(\%)\end{array}$} \\
\cline { 4 - 7 } & & & $(\mathrm{kcal} / \mathrm{mol})$ & $(\%)$ & $(\mathrm{kcal} / \mathrm{mol})$ & $(\%)$ & 66.942 \\
$(100)$ & 2 & 15.915 & -22.020 & 8.112 & -249.420 & 91.888 & 18.227 \\
$(20-2)$ & 2 & 7.654 & -65.950 & 24.296 & -205.490 & 75.704 & 3.891 \\
$(10-2)$ & 2 & 7.615 & -72.416 & 26.678 & -199.024 & 73.322 & 6.222 \\
$(110)$ & 4 & 5.881 & -148.176 & 54.589 & -123.264 & 45.411 & 1.154 \\
$(011)$ & 4 & 5.653 & -156.696 & 57.728 & -114.744 & 42.272 & 3.565 \\
$(11-1)$ & 4 & 5.849 & -158.195 & 58.280 & -113.245 & 41.720 & \\
\hline
\end{tabular}




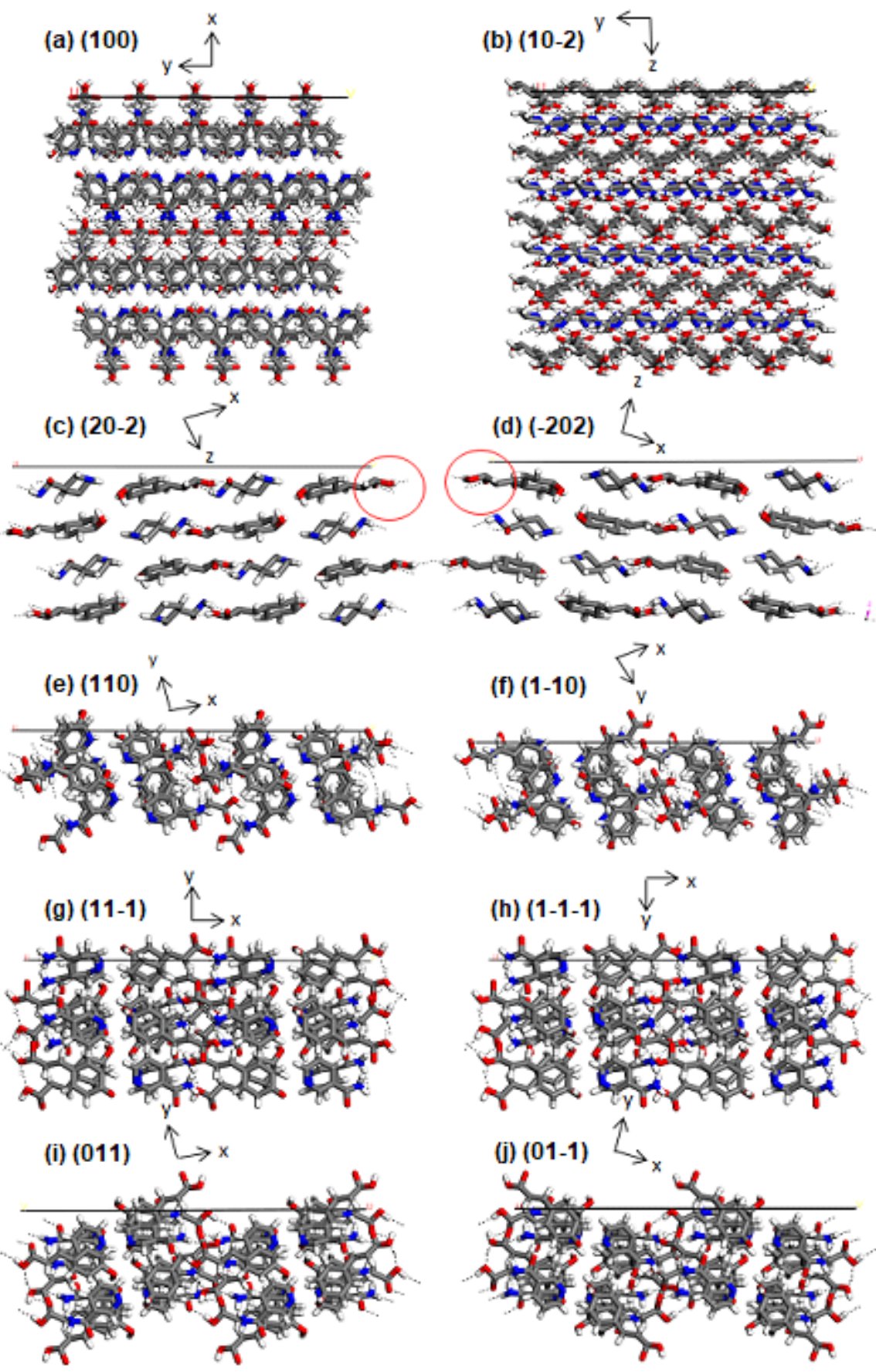

Fig 8. Molecular packing diagram of NIC:COU (1:1) cocrystal illustrating the surface chemistry of crystal facets, determined using the routine available in the Material Studio program package; forcefield used was Dreiding with ESP charge set

higher slice energy, compared to the aggregated molecular arrangements in other facets with lower slice energy. This shows that the molecular arrangement behavior within the crystal lattice has a compelling impact on the slice energy of the growing crystal.

\section{Solubility Determination}

Fig. 9 illustrates the experimental solubilitytemperature profile of NIC:COU (1:1) cocrystal compared to NIC from $10^{\circ} \mathrm{C}$ to $60^{\circ} \mathrm{C}$. The experimental solubility of NIC is within reasonable agreement with the 


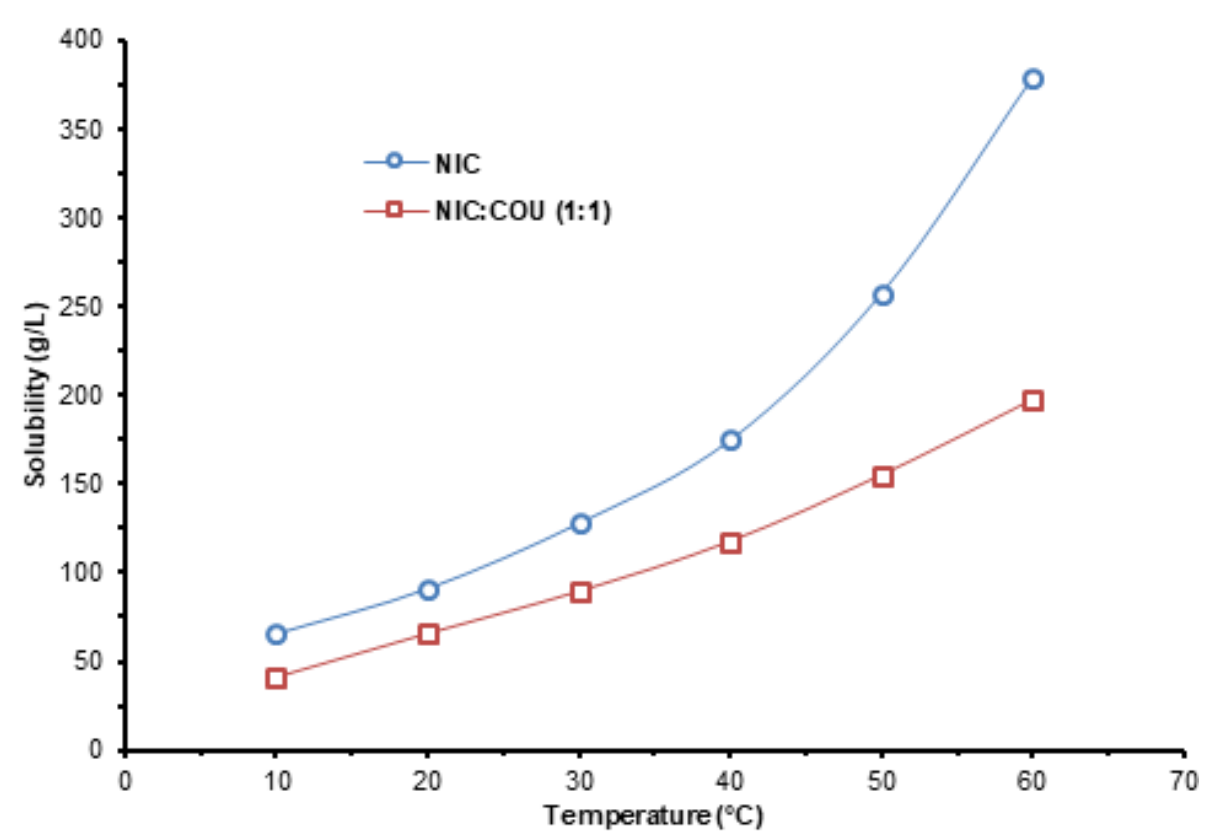

Fig 9. Solubility-temperature dependence of NIC and NIC:COU (1:1) cocrystal

result obtained by the previous researcher [67]. The solubility of NIC:COU (1:1) cocrystal significantly reduced in ethanol compared to NIC. The reduced cocrystal solubility may be due to the changes in the solvating interaction between the molecules and the solvent (varying from van der Waals to hydrogen bonding) $[5,68]$.

The solvent used in the solubility determination affects the most to the solubility result, which generally follows the solubility of solute principle, 'like dissolves like' [68]. The solubility drop may also be due to the different solvent used during the crystallization process and the solubility analysis. Acetonitrile (polarity $=46$, dielectric constant $=37.5$ ) is a polar aprotic solvent, while ethanol (polarity $=65.4$, dielectric constant $=24.3$ ) is a polar protic solvent [67]. The simulation of cocrystal facets also shows the polar functional group exposed on most of the crystal facets, which makes the crystal as a polar compound. The assessment of structural conformation between (20-2) facet with its symmetry also shows the polar facet characteristic, explaining the reduced solubility of cocrystal in ethanol.

Higher melting temperature and heat content of NIC:COU (1:1) cocrystal $\left(159.07^{\circ} \mathrm{C}\right)$ compared to the compound with higher solubility, NIC $\left(129.94{ }^{\circ} \mathrm{C}\right)$ also being one of the factors of low solubility [21]. Although the decrease in solubility was not desired in the pharmaceutical industry, it was preferred by some other application of specialty chemicals [69].

\section{Antioxidant Activity Determination}

NIC and NIC:COU (1:1) cocrystal scavenging activities were analyzed by the reduction of the stable radical DPPH to non-radical stable diamagnetic compound with the presence of hydrogen-donating antioxidant $[60,70]$. The color change observed was from purple to colorless solution, which signifies that the DPPH radical has accepted the hydrogen donated from the antioxidant sample. The results of the in vitro antioxidant capability of NIC and NIC:COU (1:1) cocrystal by DPPH radical scavenging activity assay are tabulated in Table 7. The results show the increase in the radical scavenging capability of the cocrystal at several concentrations compared to NIC individually. This confirms that the NIC:COU (1:1) cocrystal is a more effective proton donor to the DPPH radical compared to NIC. The scavenging capability increase varies from $2.23 \%$ to $77.06 \%$. The highest increment recorded is $77.06 \%$ at a concentration of $31.3 \mu \mathrm{M}$. The reported antioxidant activity of COU was $182.75 \mu \mathrm{M}$ with $55.6 \%$ inhibition [60], which is lower compared to the 
Table 7. Scavenging activity of NIC and NIC:COU (1:1) cocrystal

\begin{tabular}{rrrc}
\hline Concentration, & \multicolumn{2}{c}{$\%$ Scavenging activity } & \% Increased \\
\cline { 2 - 3 }$\mu \mathrm{M}$ & \multicolumn{1}{c}{ NIC } & NIC:COU $(1: 1)$ & scavenging activity \\
\hline 2.0 & 8.97 & 7.94 & - \\
3.9 & 8.57 & 12.34 & 43.99 \\
7.8 & 11.01 & 8.36 & - \\
15.6 & 8.68 & 9.56 & 10.14 \\
31.3 & 8.02 & 14.20 & 77.06 \\
62.5 & 9.43 & 9.64 & 2.23 \\
125.0 & 9.53 & 8.86 & - \\
250.0 & 8.61 & 13.84 & 60.74 \\
500.0 & 9.93 & 6.48 & - \\
1000.0 & 8.56 & 13.24 & 54.67 \\
\hline
\end{tabular}

synthesized cocrystal. The increased antioxidant capability of the cocrystal is due to the combined cocrystal structure of NIC and COU, which summates the number of hydrogen atom donors to react with the DPPH radical.

\section{- CONCLUSION}

The NIC:COU (1:1) cocrystal was successfully synthesized using a slow evaporation method with acetonitrile. The comparison of the crystal data between the synthesized cocrystal with the published cocrystal data revealed similar cocrystal of NIC:COU (1:1) was produced, the synthesized cocrystal showed greater stability where the melting temperature is higher than the published cocrystal. The characterization data also discovered new crystal phases for the NIC:COU cocrystals with 1:2 and 2:1 feed molar ratios, which were not successfully grown into a single crystal. The molecular dynamics simulation work predicted the morphology of the NIC:COU (1:1) cocrystal using ESP/Dreiding pair resulted in lattice energy of $-271.440 \mathrm{kcal} / \mathrm{mol}$, which was in reasonable agreement with the experimental cocrystal morphology. The predicted cocrystal morphology was characterized as elongated (along the $y$-axis) octagonal shape with 18 total crystal facets, in which the morphological importance (100) was the strongest and the (11-1) facet was the weakest. The hydrogen-bonding interactions simulated in the MS were also concurrent with the result from SCD.

Nonetheless, the solubility of the cocrystal significantly reduced as the temperature was increased in ethanol. This occurrence was assisted with the increased melting temperature of NIC:COU (1:1) cocrystal compared to the NIC with the highest solubility compound used in this study. The simulation of crystal facets also showed the exposed polar functional groups, which technically will have low solubility in less polar solvent ethanol. The NIC:COU (1:1) cocrystal was found to be an effective antioxidant in the DPPH radical assay with the highest scavenging activity increase of $77.06 \%$ compared to NIC individually at $31.3 \mu \mathrm{M}$. The improved radical scavenging capacity of NIC:COU (1:1) cocrystal offers the potential value to become a new oral or transdermal formulation with better bioavailability.

\section{- ACKNOWLEDGMENTS}

The authors would like to express their gratitude to the Ministry of Higher Education, Malaysia for funding this work, which was carried out at Universiti Teknologi MARA, Malaysia. This work was funded by research grant Geran Inisiatif Penyeliaan (GIP) [600-IRMI 5/3/GIP (003/2019)].

\section{- REFERENCES}

[1] Song, J.X., Chen, J.M., and Lu, T.B., 2015, Lenalidomide-gallic acid cocrystals with constant high solubility, Cryst. Growth Des., 15 (10), 48694875.

[2] Huang, Y., Zhang, B., Gao, Y., Zhang, J., and Shi, L., 2014, Baicalein-nicotinamide cocrystal with 
enhanced solubility, dissolution, and oral bioavailability, J. Pharm. Sci., 103 (8), 2330-2337.

[3] Cheney, M.L., Weyna, D.R., Shan, N., Hanna, M., Wojtas, L., and Zaworotko, M.J., 2010, Supramolecular architectures of meloxicam carboxylic acid cocrystals, a crystal engineering case study, Cryst. Growth Des., 10 (10), 4401-4413.

[4] Raghuram, M., Sarwar Alam, M., Prasad, M., and Has Khanduri, C., 2014, Pharmaceutical cocrystal of prulifloxacin with nicotinamide, Int. J. Pharm. Pharm. Sci., 6 (10), 180-184.

[5] Shayanfar, A., Velaga, S., and Jouyban, A., 2014, Solubility of carbamazepine, nicotinamide and carbamazepine-nicotinamide cocrystal in ethanolwater mixtures, Fluid Phase Equilib., 363, 97-105.

[6] Hino, T., Ford, J.L., and Powell, M.W., 2001, Assessment of nicotinamide polymorphs by differential scanning calorimetry, Thermochim. Acta, 374 (1), 85-92.

[7] Bevill, M.J., Vlahova, P.I., and Smit, J.P., 2014, Polymorphic cocrystals of nutraceutical compound $p$-coumaric acid with nicotinamide: Characterization, relative solid-state stability, and conversion to alternate stoichiometries, Cryst. Growth Des., 14 (3), 1438-1448.

[8] Aakeröy, C.B., Beatty, A.M., and Helfrich, B.A., 2002, A high-yielding supramolecular reaction, J. Am. Chem. Soc., 124 (48), 14425-14432.

[9] Aakeröy, C.B., Beatty, A.M., Helfrich, B.A., and Nieuwenhuyzen, M., 2003, Do polymorphic compounds make good cocrystallizing agents? A structural case study that demonstrates the importance of synthon flexibility, Cryst. Growth Des., 3 (2)., 159-165.

[10] Bhogala, B.R., Basavoju, S., and Nangia, A., 2005, Tape and layer structures in cocrystals of some diand tricarboxylic acids with 4,4'-bipyridines and isonicotinamide. From binary to ternary cocrystals, CrystEngComm, 7 (90), 551-562.

[11] Fábián, L., Hamill, N., Eccles, K.S., Moynihan, H.A., Maguire, A.R., McCausland, L., and Lawrence, S.E., 2011, Cocrystals of fenamic acids with nicotinamide, Cryst. Growth Des., 11 (8), 3522-3528.
[12] Lemmerer, A., Báthori, N.B., and Bourne, S.A., 2008, Chiral carboxylic acids and their effects on melting-point behaviour in co-crystals with isonicotinamide, Acta Crystallogr., Sect. B: Struct. Sci., 64 (Pt 6), 780-790.

[13] Vishweshwar, P., Nangia, A., and Lynch, V.M., 2003, Supramolecular synthons in phenolisonicotinamide adducts, CrystEngComm, 5 (31), 164-168.

[14] Vishweshwar, P., Nangia, A., and Lynch, V.M., 2003, Molecular complexes of homologous alkanedicarboxylic acids with isonicotinamide: Xray crystal structures, hydrogen bond synthons, and melting point alternation, Cryst. Growth Des., 3 (5), 783-790.

[15] Berry, D.J., Seaton, C.C., Clegg, W., Harrington, R.W., Coles, S.J., Horton, P.N., Hurtshouse, M.B., Storey, R., Jones, W., and Friscic, T., 2008, Applying hot-stage microscopy to co-crystal screening: A study of nicotinamide with seven active pharmaceutical ingredients, Cryst. Growth Des., 8 (5), 1697-1712.

[16] Zhang, S.W., Harasimowicz, M.T., de Villiers, M.M., and Yu, L., 2013, Cocrystals of nicotinamide and (R)-mandelic acid in many ratios with anomalous formation properties, J. Am. Chem. Soc., 135 (50), 18981-18989.

[17] Setyawan, D., Sari, R., Yusuf, H., and Primaharinastiti, R., 2014, Preparation and characterization of artesunate-nicotinamide cocrystal by solvent evaporation and slurry method, Asian J. Pharm. Clin. Res., 7 (Suppl. 1), 62-65.

[18] Rahman, Z., Agarabi, C., Zidan, A.S., Khan, S.R., and Khan, M.A., 2011, Physico-mechanical and stability evaluation of carbamazepine cocrystal with nicotinamide, AAPS PharmSciTech, 12 (2), 693704.

[19] Remenar, J.F., Peterson, M.L., Stephens, P.W., Zhang, Z., Zimenkov, Y., and Hickey, M.B., 2007, Celecoxib: Nicotinamide dissociation: Using excipients to capture the cocrystal's potential, Mol. Pharmaceutics, 4 (3), 386-400. 
[20] Nicoli, S., Bilzi, S., Santi, P., Caira, M. R., Li, J., and Bettini, R., 2008, Ethyl-paraben and nicotinamide mixtures: Apparent solubility, thermal behavior and X-ray structure of the 1:1 co-crystal, J. Pharm. Sci., 97 (11), 4830-4839.

[21] Sopyan, I., Fudholi, A., Muchtaridi, M., and Sari, I.P., 2017, Simvastatin-nicotinamide co-crystal: Design, preparation and preliminary characterization, Trop. J. Pharm. Res., 16 (2), 297-303.

[22] Keramatnia, F., Shayanfar, A., and Jouyban, A., 2015, Thermodynamic solubility profile of carbamazepinecinnamic acid cocrystal at different pH, J. Pharm. Sci., 104 (8), 2559-2565.

[23] Shayanfar, A., Asadpour-Zeynali, K., and Jouyban, A., 2013, Solubility and dissolution rate of a carbamazepine-cinnamic acid cocrystal, J. Mol. Liq., 187, 171-176.

[24] Lemmerer, A., Esterhuysen, C., and Bernstein, J., 2010, Synthesis, characterization, and molecular modeling of a pharmaceutical co-crystal: (2-Chloro4-nitrobenzoic acid):(nicotinamide), J. Pharm. Sci., 99 (9), 4054-4071.

[25] Etter, M.C., 1990, Encoding and decoding hydrogenbond patterns of organic compounds, Acc. Chem. Res., 23 (4), 120-126.

[26] Bernstein, J., Davis, R.E., Shimoni, L., and Chang, N.L., 1995, Patterns in hydrogen bonding: Functionality and graph set analysis in crystals, Angew. Chem. Int. Ed., 34 (15), 1555-1573.

[27] Etter, M.C., MacDonald, J.C., and Bernstein, J., 1990, Graph-set analysis of hydrogen-bond patterns in organic crystals, Acta Crystallogr., Sect. B: Struct. Sci., 46, 256-262.

[28] Karki, S., Friščić, T., and Jones, W., 2009, Control and interconversion of cocrystal stoichiometry in grinding: Stepwise mechanism for the formation of a hydrogen-bonded cocrystal, CrystEngComm, 11 (3), 470-481.

[29] Nićiforović, N., and Abramovič, H., 2014, Sinapic acid and its derivatives: Natural sources and bioactivity, Compr. Rev. Food Sci. Food Saf., 13 (1), 34-51.
[30] Kulik, T.V., Lipkovska, N.O., Barvinchenko, V.M., Palyanytsya, B.B., Kazakova, O.A., Dudik, O.O., Menyhard, A., and Laszlo, K., 2016, Thermal transformation of bioactive caffeic acid on fumed silica seen by UV-Vis spectroscopy, thermogravimetric analysis, temperature programmed desorption mass spectrometry and quantum chemical methods, J. Colloid Interface Sci., 470, 132-141.

[31] Schultheiss, N., Roe, M., and Boerrigter, S.X.M., 2011, Cocrystals of nutraceutical p-coumaric acid with caffeine and theophylline: polymorphism and solid-state stability explored in detail using their crystal graphs, CrystEngComm, 13 (2), 611-619.

[32] Ravikumar, N., Gaddamanugu, G., and Solomon, K.A., 2013, Structural, spectroscopic (FT-IR, FTRaman) and theoretical studies of the 1:1 cocrystal of isoniazid with p-coumaric acid, J. Mol. Struct., 1033, 272-279.

[33] Du, N., Cao, S., and Yu, Y., 2011, Research on the adsorption property of supported ionic liquids for ferulic acid, caffeic acid and salicylic acid, J. Chromatogr. B, 879 (19), 1697-1703.

[34] Kumar, N., Pruthi, V., and Goel, N., 2015, Structural, thermal and quantum chemical studies of $p$-coumaric and caffeic acids, J. Mol. Struct., 1085, 242-248.

[35] Jacobs, A., and Noa, F.M.A., 2013, Hybrid saltcocrystal solvate: p-coumaric acid and quinine system, J. Chem. Crystallogr., 44 (2), 57-62.

[36] Swapna, B., Maddileti, D., and Nangia, A., 2014, Cocrystals of the tuberculosis drug isoniazid: Polymorphism, isostructurality, and stability, Cryst. Growth Des., 14 (11), 5991-6005.

[37] Shi, W., Xia, M., Lei, W., and Wang, F., 2014, Solvent effect on the crystal morphology of 2,6diamino-3,5-dinitropyridine-1-oxide: A molecular dynamics simulation study, J. Mol. Graphics Modell., 50, 71-77.

[38] Zhang, M., Liang, Z., Wu, F., Chen, J.F., Xue, C., and Zhao, H., 2017, Crystal engineering of ibuprofen compounds: From molecule to crystal 
structure to morphology prediction by computational simulation and experimental study, $J$. Cryst. Growth, 467, 47-53.

[39] Chen, G., Xia, M., Lei, W., Wang, F., and Gong, X., 2014, Prediction of crystal morphology of cyclotrimethylene trinitramine in the solvent medium by computer simulation: A case of cyclohexanone solvent, J. Phys. Chem. A, 118 (49), 11471-11478.

[40] Han, G., Li, Q.F., Gou, R.J., Zhang, S.H., Ren, F.D., Wang, L., and Guan, R., 2017, Growth morphology of CL-20/HMX cocrystal explosive: Insights from solvent behavior under different temperatures, $J$. Mol. Model., 23 (12), 360.

[41] Hassan, S., Adam, F., Abu Bakar, M.R., and Abdul Mudalip, S.K., 2018, Evaluation of solvents' effect on solubility, intermolecular interaction energies and habit of ascorbic acid crystals, J. Saudi Chem. Soc., 23 (2), 239-248.

[42] Hod, I., Mastai, Y., and Medina, D.D., 2011, Effect of solvents on the growth morphology of dl-alanine crystals, CrystEngComm., 13 (2), 502-509.

[43] Wang, C., Zhang, X., Du, W., Huang, Y.H., Guo, M.X., Li, Y., Zhang, Z.X., Hou, B.H., and Yin, Q.X., 2016, Effects of solvent and supersaturation on crystal morphology of cefaclor dihydrate: A combined experimental and computer simulation study, CrystEngComm., 18 (47), 9085-9094.

[44] Rohl, A.L., 2003, Computer prediction of crystal morphology, Curr. Opin. Solid State Mater. Sci., 7 (1), 21-26.

[45] Liu, J., Sun, J., Zhang, H., and Wen, Y., 2016, Prediction of crystal morphology of 1,3,5-triamino2,4,6-trinitrobenzene in dimethyl sulfoxide via modified attachment energy modeling and its experimental validation, Mol. Cryst. Liq. Cryst., 634 (1), 97-103.

[46] Liu, N., Li, Y.N., Zeman, S., Shu, Y.J., Wang, B.Z., Zhou, Y.S., Zhao, Q.L., and Wang, W.L., 2016, Crystal morphology of 3,4-bis(3-nitrofurazan-4yl)furoxan (DNTF) in a solvent system: Molecular dynamics simulation and sensitivity study, CrystEngComm., 18 (16), 2843-2851.
[47] Rosbottom, I., Roberts, K.J., and Docherty, R., 2015, The solid state, surface and morphological properties of $p$-aminobenzoic acid in terms of the strength and directionality of its intermolecular synthons, CrystEngComm, 17 (30), 5768-5788.

[48] Coombes, D.S., Catlow, C.R.A., Gale, J.D., Hardy, M.J., and Saunders, M.R., 2002, Theoretical and experimental investigations on the morphology of pharmaceutical crystals, J. Pharm. Sci., 91 (7), 16521658.

[49] ter Horst, J.H., Kramer, H.J.M., van Rosmalen, G.M., and Jansens, P.J., 2002, Molecular modelling of the crystallization of polymorphs. Part I: The morphology of HMX polymorphs, J. Cryst. Growth, 237-239, 2215-2220.

[50] Erk, P., 2001, Crystal design of organic pigments-A prototype discipline of materials science, Curr. Opin. Solid State Mater. Sci., 5 (2-3), 155-160.

[51] Millan, A., 2001, Crystal growth shape of whewellite polymorphs: Influence of structure distortions on crystal shape, Cryst. Growth Des., 1 (3), 245-254.

[52] Grimsey, I.M., Osborn, J.C., Doughty, S.W., York, P., and Rowe, R.C., 2002, The application of molecular modelling to the interpretation of inverse gas chromatography data, J. Chromatogr. A, 969 (12), 49-57.

[53] Anuar, N., Wan Daud, W.R., Roberts, K.J., Kamarudin, S.K., and Tasirin, S.M., 2012, Morphology and associated surface chemistry of Lisoleucine crystals modeled under the influence of L-leucine additive molecules, Cryst. Growth Des., 12 (5), 2195-2203.

[54] Shen, F., Lv, P., Sun, C., Zhang, R., and Pang, S., 2014, The crystal structure and morphology of 2,4,6,8,10,12-hexanitro-2,4,6,8,10,12-

hexaazaisowurtzitane (CL-20) p-xylene solvate: A joint experimental and simulation study, Molecules, 19 (11), 18574-18589.

[55] McMahon, J.A., Bis, J.A., Vishweshwar, P., Shattock, T.R., McLaughlin, O.L., and Zaworotko, M.J., 2005, Crystal engineering of the composition of pharmaceutical phases. 3. Primary amide supramolecular heterosynthons and their role in 
the design of pharmaceutical co-crystals, $Z$. Kristallogr. Cryst. Mater., 220 (4), 340-350.

[56] Aitipamula, S., Chow, P.S., and Tan, R.B.H., 2009, Trimorphs of a pharmaceutical cocrystal involving two active pharmaceutical ingredients: potential relevance to combination drugs, CrystEngComm, 11 (9), 1823-1827.

[57] Spek, A.L., 2003, Single-crystal structure validation with the program PLATON, J. Appl. Crystallogr., 36 (1), 7-13.

[58] Shahidi, F., and Zhong, Y., 2015, Measurement of antioxidant activity, J. Funct. Foods, 18, 757-781.

[59] Chen, Z., Bertin, R., and Froldi, G., 2013, EC 50 estimation of antioxidant activity in DPPH assay using several statistical programs, Food Chem., 138 (1), 414-420.

[60] Kiliç, I., and Yeşiloğlu, Y., 2013, Spectroscopic studies on the antioxidant activity of $p$-coumaric acid, Spectrochim. Acta, Part A, 115, 719-724.

[61] Gholizadeh, R., Wang, Y., and Yu, Y.X., 2017, Molecular dynamics simulations of stability at the early stages of silica materials preparation, J. Mol. Struct., 1138, 198-207.

[62] Manin, A.N., Voronin, A.P., Drozd, K.V., Manin, N.G., Bauer-Brandl, A., and Perlovich, G.L., 2014, Cocrystal screening of hydroxybenzamides with benzoic acid derivatives: A comparative study of thermal and solution-based methods, Eur. J. Pharm. Sci., 65, 56-64.

[63] Ezawa, T., Kawashima, Y., Noguchi, T., Jung, S., and Imai, N., 2017, Amidation of carboxylic acids via the mixed carbonic carboxylic anhydrides and its application to synthesis of antidepressant (1S,2R)tranylcypromine, Tetrahedron: Asymmetry, 28 (12), 1690-1699.

[64] Teranishi, K., 2016, trans-p-Hydroxycinnamic acid as a bioluminescence-activating component in the pileus of the luminous fungus Mycena chlorophos, Tetrahedron., 72 (5), 726-733.

[65] Ren, C., Li, X., and Guo, L., 2019, Chemical insight on decreased sensitivity of CL-20/TNT cocrystal revealed by ReaxFF MD simulations, J. Chem. Inf. Model., 59 (5), 2079-2092.

[66] Singh, M., 2006, First principle study of crystal growth morphology: An application to crystalline urea, arXiv:cond-mat.mtrl-sci, 0602385.

[67] Wu, H., Dang, L., and Wei, H., 2014, Solid-liquid phase equilibrium of nicotinamide in different pure solvents: Measurements and thermodynamic modeling, Ind. Eng. Chem. Res., 53 (4), 1707-1711.

[68] Ji, W., Meng, Q., Ding, L., Wang, F., Dong, J., Zhou, G., and Wang, B., 2016, Measurement and correlation of the solubility of caffeic acid in eight mono and water + ethanol mixed solvents at temperatures from (293.15 to 333.15) K, J. Mol. Liq., 224, 1275-1281.

[69] Aakeröy, C.B., Forbes, S., and Desper, J., 2009, Using cocrystals to systematically modulate aqueous solubility and melting behavior of an anticancer drug, J. Am. Chem. Soc., 131 (47), 17048-17049.

[70] Gülçin, I., 2006, Antioxidant activity of caffeic acid (3,4-dihydroxycinnamic acid), Toxicology, 217 (23), 213-220. 